\title{
Güncel Politikalar Çerçevesinde Kent İçi Karayolu Trafik Güvenliği
}

$*$

\author{
Ozan Kavsirac1 \\ Polis Akademisi
}

Öz

Günümüzde kentler, iktisadi faaliyetlerin yoğun olarak gerçekleştiği ve dolayısı ile ikamet olarak fazlaca tercih edilen yerlerdir. Kentlerin nüfus yoğunluğu, hızl nüfus artışı ile birlikte değerlendirildiğinde, karayolu ulaşım faaliyetleri ve beraberinde getirdiği kaza riskleri önemli bir sorun olarak karşımıza çıkmaktadır. Trafik kazalarının maddi ve manevi olası zararlarım en aza indirmek noktasında, trafikte sürücü, yaya, yolcu ve denetim personeli olarak karşımıza çıkan insan faktörü öncelikli olarak değerlendirilmelidir. Bu kapsamda trafik güvenliği çerçevesinde farkındalık oluşturmak için eğitim, kampanya ve denetim faaliyetleri öne çıkmaktadır. Bu çalışmada kent içi karayolu trafik güvenliği özelinde risk faktörleri incelenmiştir. Risk faktörlerine yönelik politikalara değinilerek trafik kazalarmm birey ve kent güvenliği için sebep olduğu tehdidin boyutu ve bu tehdide karşı geliştirilen ulaşım politikaları incelenmiştir. BM'nin trafik güvenliği noktasında geliştirdiği eylem planı çerçevesinde Türkiye'de uygulamaya geçirilen güncel trafik güvenliği politikaları analiz edilmiştir. Bu kapsamda Türkiye trafik kazalarının neden olduğu maddi ve manevi kayıpları minimum seviyeye çekme noktasında Birleşmiş Milletlerin (BM) tavsiye kararlarına yönelik geliştirilen politikaları hassasiyetle yürütmektedir. Bu çalışma, kent içi karayolu trafik güvenliğine yönelik geliştirilen politikaların, trafik kazalarına ilişkin risk faktörlerini minimize etme noktasındaki etkinliğinin değerlendirilmesine katkı sağlayacaktır.

Anahtar kelimeler: Karayolu, kent, trafik güvenliği, trafik kazası, ulaşım.

idealkent (c) Kent Araştırmaları Dergisi (Journal of Urban Studies)

http://idealkentdergisi.com

Geliş Tarihi Received Date: 07.11.2017 Kabul Tarihi Accepted Date: 30.12.2018 


\title{
City-Road Traffic Safety in the Framework of Current Policies
}

\author{
* \\ Ozan Kavsirac1 \\ Turkish National Police Academy
}

\begin{abstract}
Nowadays, cities are the places where economic activities are intense and therefore they are mostly preferred places of residence. When the population density of the cities is evaluated together with the rapid population increase, the road transport activities and the risk of accidents which they cause come up as a significant problem. In terms of minimizing the physical and spiritual damages of traffic accidents, the human factor which is encountered in the traffic as driver, pedestrian, passenger and inspection personnel should be considered as priority. In this context, education, campaign and auditing activities come to the fore in order to raise awareness in the context of traffic safety. In this study, risk factors for urban road traffic safety have been examined. By addressing the policies for risk factors, the extent of the threat posed by the traffic accidents to the individual and urban safety, the transportation policies developed against this threat have been examined. Within the framework of the United Nations (UN) road safety action plan, current traffic safety policies implemented in Turkey has been analyzed. In this context, Turkey carries out the policies developed for the UN's recommendation decisions at the point of minimizing the physical and spiritual losses caused by traffic accidents. This study, will contribute to the evaluation of the effectiveness of policies developed for urban road traffic safety in minimizing risk factors related to traffic accidents.
\end{abstract}

Keywords: Highway, city, traffic safety, traffic accident, transportation. 


\section{Giriş}

Kentlerde yapılaşmanın hız kazanması, gerçekleşen hızlı nüfus artışı ile birlikte, kentlerin geniş alanlara yayılmasını ve ulaşım araçlarını kullanma zorunluluğunu beraberinde getirmiştir. Ancak kentsel yaşamın hızlı gelişimi ile ulaşım sistemlerinin erişilebilirliği doğru orantılı olarak gelişim gösterememiştir. Bu süreç kent sakinleri için artarak devam eden bir trafik sorunu ortaya çıkarmaktadır (Akbulut, 2016, s. 337). Ortaya çıkan bu trafik sorunu devletler ve bireyler için maddi, manevi kayıplara neden olmaktadır. Bu sebeple önemli kayıplara neden olan trafik sorununa çözüm getirerek karayolu trafik güvenliğini sağlamak, devlet yönetimleri için aşılması gereken önemli bir toplumsal sorun haline gelmiştir. Karayolu trafik güvenliği; çevre, taşıt ve insan bileşenleri arasında çıkabilecek muhtemel sorunları ve bu sorunlara karşı geliştirilen yöntemleri içeren çok yönlü bir konudur (Payam, 2012, s. 19). Karayolu trafik güvenliği, trafiği oluşturan; araç, yol, yol kullanıcısı ve bunların içinde bulunduğu fiziksel ve sosyal çevre arasındaki etkileşimin anlaşılmasını, risk teşkil eden konuların düzeltilmesini kapsamaktadır. Türkiye'de yük ve yolcu taşımacılığının yaklaşık \%90'ının karayolları vasıtasıyla gerçekleştirilmesi ve aşağıda belirtildiği üzere trafiğe hızla yeni araçların katılması, trafik kazası riskinin yüksek seviyelerde seyretmesine neden olmakta ve karayolu trafik güvenliğini daha önemli hale getirmektedir.

Tablo 1. Türkiye' de Motorlu Kara Taşıt Sayısı

\begin{tabular}{ccccc}
\hline Yıl & $\begin{array}{c}\text { Toplam Motorlu } \\
\text { Kara Taşı Sayıs }\end{array}$ & Özel Otomobil & Minibüs & Otobüs \\
\hline 2008 & 13765395 & 6796629 & 383548 & 199934 \\
\hline 2009 & 14316700 & 7093964 & 384053 & 201033 \\
\hline 2010 & 15095603 & 7544871 & 386973 & 208510 \\
\hline 2011 & 16089528 & 8113111 & 389435 & 219906 \\
\hline 2012 & 17033413 & 8648875 & 396119 & 235949 \\
\hline 2013 & 17939447 & 9283923 & 421848 & 219885 \\
\hline 2014 & 18828721 & 9857915 & 427264 & 211200 \\
\hline 2015 & 19994472 & 10589337 & 449213 & 217056 \\
\hline 2016 & 21090424 & 11317998 & 463933 & 220361 \\
\hline 2017 & 22218945 & 12035978 & 478618 & 221885 \\
\hline
\end{tabular}

Kaynak: Türkiye İstatistik Kurumu (TÜİK) 
Türkiye'de trafiğe kayıtlı motorlu kara taşıt sayısı, 2008 ile 2017 yıllarını kapsayan on yıllık süre içerisinde yaklaşı $\% 65$ oranında artış göstermiştir. 2017'de bir önceki yıla göre taşıt sayısındaki artış oranı ise \%5,4 olmuştur. 2017 yılı itibari ile trafikteki taşıtların \%54,1'ini otomobil, \%16,4'ünü kamyonet, \%14'ünü motosiklet, \%8,3'ünü traktör, \%3,8'ini kamyon, \%2,2'sini minibüs, \%1'ini otobüs, yüzde 0,2'sini ise özel amaçlı taşıtlar oluşturmaktadır. Türkiye'de yük ve yolcu taşımacılığının ağırlıklı olarak karayolları ile gerçekleştirilmesi, trafiğe kayıtlı taşıt sayısındaki artışı tetiklemektedir. Motorlu taşıt sayısının yukarıda ifade edildiği üzere sürekli artması, trafik kazalarının meydana gelme riskini de arttırmaktadır.

Bu çalışma ile trafik kazalarının neden olduğu maddi ve manevi kayıpların minimize edilmesi için uygulamaya geçirilen politikalar ve bu politikaların etkinliğinin analiz edilmesi amaçlanmaktadır. Dört bölümden oluşan bu çalışmanın birinci bölümünde kent içi karayolu trafiği ile ilgili temel kavramlar ve trafik kazalarının maliyetleri açıklanmıştır. İkinci bölümde sürdürülebilir kent içi karayolu ulaşım politikaları, geleneksel ve çağdaş yaklaşımlar çerçevesinde ifade edilmiştir. Üçüncü bölümde karayolu trafik güvenliği için risk teşkil eden temel faktörler incelenmiş ve son bölümde ise Türkiye'de karayolu trafik güvenliği yönetiminde uygulamaya geçirilen güncel politikalar analiz edilmiştir. Bu çalışma, kent içi karayolu trafik güvenliğine yönelik geliştirilen politikaların, trafik kazalarına ilişkin risk faktörlerini minimize etme noktasındaki etkinliğinin değerlendirilmesi noktasinda önem arz etmektedir.

\section{Kentsel Karayolu Ulaşımı, Trafik Kazaları ve Maliyetler}

Bir kentte meydana gelen, özel, kamu, kişisel, toplu, ticari ve ticari olmayan tüm ulaşım faaliyetleri ve bu faaliyetler ile ilişkili alt yapı, üst yapı, yönetim, koordinasyon unsurları kentsel ulaşım tanımı altında değerlendirilmektedir. Kentlerin otomobil ile tanışması sonucu, trafik kazalarının neden olduğu riskler başta olmak üzere bir takım temel kentsel sorunlar ortaya çlkmıştır. Kentsel ulaşımın temelinde karayolları bulunmaktadır. Bunun yanında raylı sistemler ve deniz, suyolları da kentsel ulaşıma hizmet etmektedir (Şenbil, 2016, s. 260-262). Kentsel ulaşım alanındaki kapasite ve yönetim eksikliği, ulaşım sorun ve tehditlerini daha fazla hissedilir duruma getirmektedir. Kentler, iktisadi faaliyetlerin yoğun olarak gerçekleştirildiği ve dolayısı ile nüfusun büyük kısmının ikamet ettiği yerlerdir. Bu sebeple kent merkezlerinin yaya ve araç trafiği oldukça fazladır. İnsan yoğunluğunun 
fazla olması, trafik kazası riskinin artmasını da beraberinde getirmektedir. Çünkü Türkiye ve dünyada meydana gelen trafik kazalarına bakıldığında en büyük kusur payının insana ait olduğu görülmektedir. Sadece sürücü olarak değil yaya ve yolcu olarak da trafiğe katılanları değerlendirdiğimizde trafik kazalarında insanın oynadığı rolün ne kadar önemli olduğu anlaşılmaktadır (Özdemir, 2010, s. 11). Bu sebeple insanın trafik kazalarında oynadığı rolü azaltarak kent içi karayolu trafik güvenliğine katkı sağlama noktasında trafik yönetimi önemli bir konu haline gelmektedir.

Tablo 2. Türkiye'de Trafik Kazalarına Neden Olan Kusurlar

\begin{tabular}{cccccc}
\hline Yil & $\begin{array}{c}\text { Sürücü Kusuru } \\
\mathbf{( \% )}\end{array}$ & $\begin{array}{c}\text { Yolcu Kusuru } \\
\mathbf{( \% )}\end{array}$ & $\begin{array}{c}\text { Yaya Kusuru } \\
\mathbf{( \% )}\end{array}$ & $\begin{array}{c}\text { Yol Kusuru } \\
\mathbf{( \% )}\end{array}$ & $\begin{array}{c}\text { Araç Kusuru } \\
\mathbf{( \% )}\end{array}$ \\
\hline 2008 & 90,53 & 0,43 & 8,37 & 0,42 & 0,26 \\
\hline 2009 & 89,60 & 0,41 & 9,09 & 0,61 & 0,29 \\
\hline 2010 & 89,72 & 0,39 & 9,86 & 0,69 & 0,36 \\
\hline 2011 & 90,20 & 0,39 & 8,51 & 0,60 & 0,30 \\
\hline 2012 & 88,86 & 0,44 & 9,75 & 0,62 & 0,33 \\
\hline 2013 & 88,69 & 0,42 & 8,99 & 1,05 & 0,85 \\
\hline 2014 & 88,62 & 0,47 & 9,38 & 0,95 & 0,58 \\
\hline 2015 & 89,30 & 0,43 & 8,80 & 0,91 & 0,55 \\
\hline 2016 & 89,59 & 0,41 & 8,73 & 0,81 & 0,47 \\
\hline 2017 & 89,87 & 0,37 & 8,48 & 0,70 & 0,52 \\
\hline
\end{tabular}

Kaynak: Türkiye İstatistik Kurumu (TÜİK)

Trafik kazalarına neden olan kusur oranlarına bakıldığında; insan, araç ve çevre bileşenleri içerisinde, insan unsuru (sürücü, yolcu ve yaya), \%98,7 kusur oranı ile dikkat çekmektedir. İstatistiklere göre, $\% 89,8$ oranı ile en büyük kusur payı ise sürücülerindir. Trafik kazalarında, kusur oranlarının belirlenmesinde, kaza yerinin fotoğrafı, topografyası, yol verileri ve eğimleri önem arz etmektedir. Bu çerçevede farklı disiplinlere ait verilerin toplanması için özelikle ölümlü ve yaralamalı kazalarda derinlemesine inceleme ekiplerinin görevlendirilmesi, kusur oranlarının daha doğru olarak tespit edilmesine hizmet edecektir. Tablo-2'de ifade edildiği üzere, kazalarda en büyük kusur oran insan bileşenine aittir. Bu durum sürücü ve diğer yol kullanıcılarının davranış, beceri, tutum ve diğer kişisel özelliklerinin trafik kazaları ile etkileşiminin detaylı olarak incelenmesi gerektiğini göstermektedir. 
20. yy. da ulaşım şampiyonu olan motorlu taşıtlar arasında özel otomobiller, bir ulaşım aracı olmasının yanında günümüzde toplumsal statü için de kullanılan bir araç haline gelmiştir. Tablo 1. de belirtildiği üzere son 10 yıllık süreç içerisinde özel otomobil sayısı ikiye katlanmış ve 2017 yılı itibari ile toplam özel otomobil sayısı 12035 978' e ulaşmıştır. Türkiye' de otomobil sayısının hızlı artışı trafik kazalarının ve trafik kazaları sonucu ölüm ve yaralanmaların artışını beraberinde getirmiştir. Dünya Sağlık Örgütü verilerine göre dünyada her yıl ortalama 1 milyon 250 bin insan trafik kazalarında hayatını kaybetmektedir. Bu rakam dikkate alındığında, hayatımızın önemli bir parçası olan karayolu trafiği, birey ve kent güvenliğinin en büyük tehditlerinden biri haline gelmektedir. Aşağıda Tablo.3' de son on yıllık süre içerisinde Türkiye'de meydana gelen trafik kazaları, toplam taşıt sayısı, yaralı ve ölüm sayıları gösterilmektedir.

Tablo 3. Türkiye'de Trafik Kazası, Taşıt, Ölü ve Yaralı Sayısı

\begin{tabular}{ccccccc}
\hline Yıl & $\begin{array}{c}\text { Motorlu Kara } \\
\text { Taşıt Sayısı }\end{array}$ & $\begin{array}{c}\text { Toplam } \\
\text { Kaza Sa- } \\
\text { yısı }\end{array}$ & Ölü Sayısı & $\begin{array}{c}\text { Kaza Ye- } \\
\text { rinde Ölü } \\
\text { Sayısı }\end{array}$ & $\begin{array}{c}\text { Kaza Son- } \\
\text { rası Ölü } \\
\text { Sayıs }\end{array}$ & $\begin{array}{c}\text { Yaralı Sa- } \\
\text { yısı }\end{array}$ \\
\hline 2008 & 13765395 & 950120 & 4236 & 4236 & - & 184468 \\
\hline 2009 & 14316700 & 1053346 & 4324 & 4324 & - & 201380 \\
\hline 2010 & 15095603 & 1106201 & 4045 & 4045 & - & 211496 \\
\hline 2011 & 16089528 & 1228928 & 3835 & 3835 & - & 238074 \\
\hline 2012 & 17033413 & 1296634 & 3750 & 3750 & - & 268079 \\
\hline 2013 & 17939447 & 1207354 & 3685 & 3685 & - & 274829 \\
\hline 2014 & 18828721 & 1199010 & 3524 & 3524 & - & 285059 \\
\hline $2015 *$ & 19994472 & 1313359 & 7530 & 3831 & 3699 & 304421 \\
\hline 2016 & 21090424 & 1182491 & 7300 & 3493 & 3807 & 303812 \\
\hline 2017 & 22218945 & 1202716 & 7427 & 3534 & 3893 & 300383 \\
\hline
\end{tabular}

Kaynak: Türkiye İstatistik Kurumu (TÜİK)

Tablo-3'de trafik kazalarının yıllara göre değişimine bakıldığında bir artış olduğu gözlemlenmektedir. Ancak trafik kazları, motorlu taşıt sayısındaki artış

* Ölü sayıları, 2015 yılına kadar sadece kaza yerinde tespit edilen ölümleri kapsamaktadır. 2015 yılından itibaren trafik kazasında yaralanıp sağlık kuruluşuna sevk edilenlerden kazanın sebep ve tesiriyle 30 gün içinde ölenler, trafik kazalarındaki ölüm sayısına dâhil edilmektedir. 
ile birlikte değerlendirildiğinde; orantısal olarak kaza ve ölüm oranlarında azalma olduğu ortaya çıkmaktadır. Bu kapsamda şekil-1, trafik kazalarının toplam taşıta oranlanması ile yıllara göre gerçekleşen değişimi göstermektedir. Bu çerçevede karayolları özelinde gerçekleştirilen yatırımların, trafik kazalarının azaltılması noktasında olumlu bir çizgi yakaladığını söylemek mümkündür.

Şekil 1. Trafik Kazalarının Toplam Taşıta Oranı (\%0)

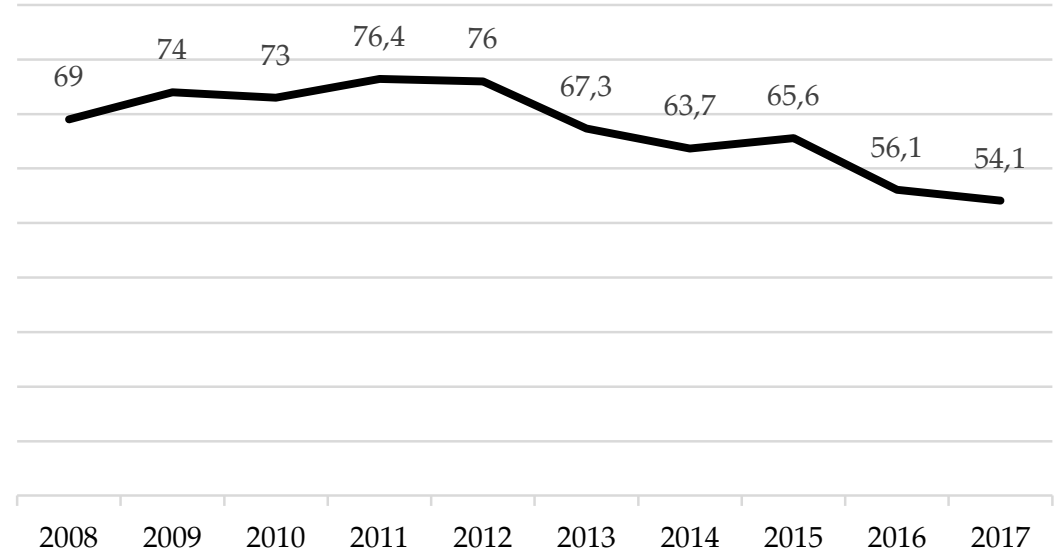

Trafik güvenliği, bütüncül olarak değerlendirildiğinde insan ilişkileri ve trafik kazaları noktasında birçok ülkede olduğu gibi Türkiye'de de önemli toplumsal konulardan biridir. Trafik kazaları sonucu meydana gelen ölüm, yaralanma ve maddi hasarlar devletler açısından çok yönlü maliyetler ortaya çıarmaktadır (Özdemir, 2010, s. 4). Kent içi trafik güvenliğine tehdit oluşturan trafik kazalarının yol açtığı hasar ve kayıplar, bireyler, ülkeler ve devlet ekonomileri açısından önemli sorunlara neden olmaktadır. Trafik kazalarının neden olduğu kayıpları aşağıdaki şekliyle ifade etmek mümkündür (Yurdakul, Turan ve Çomaklı, 2017, s. 23-25):

- Çalışan ve ekonomik olarak verimli olan nüfusun trafik kazaları sonucunda yaralanmaları, sakat kalmaları, ölümleri iş gücü kaybına neden olmaktadır. Kalifiye iş gücünün kaybedilmesi ekonomik büyüme ve gelişmeyi olumsuz etkilemektedir. Ayrıca kaza kurbanlarının yaşam kalitelerinin düşmesi, ailelerinin ve yakın çevrelerinin çektiği acı, keder manevi olarak önemli sorunlara neden olmaktadır.

- Trafik kazaları sağlık harcamalarının artmasına neden olmaktadır. Yaralanma sonucu ortaya çıkan bedensel hasarların giderilmesi için özel 
sağlık ve SGK yoluyla finanse edilen sağlik harcamaları bireyler ve devlet açısından önemli bir maliyet ortaya çıkarmaktadır.

- Trafik kazaları sonucu ortaya çıan kent içi trafik sıkışıklığı zaman kaybına neden olmaktadır. Bu zaman kaybı polis, ambulans ve diğer sürücüler için acil konularda aksamaya neden olmaktadır. Trafikte yaşanan aksamalar hem ekonomiyi hem de toplum sağlığını olumsuz etkilemektedir.

- Trafik kazaları kamu harcamalarının artmasına neden olmaktadır. Kaza sonrası araç, yol, bariyer, trafik ışıkları, levhalar gibi unsurlarda meydana gelen hasarların giderilmesi, bakımı ve kaza sonrasında görevlendirilen bilirkişi giderleri kamu harcamalarında önemli bir artışa neden olmaktadir.

- Trafik kazaları sonrasında kasko, zorunlu trafik sigortaları, hayat sigortaları gibi harcamalar da artış göstermektedir. Sigorta şirketleri risk primi üzerinden çalıştıkları için meydana gelen olumsuzluklarda sigorta için ödenen miktarlar artmaktadır. Bunun yanında ödenen tazminatlar da ekonomik maliyetleri arttırmaktadır.

\section{Sürdürülebilir Kentsel Karayolu Ulaşım Politikası}

Sürdürülebilirlik, günün ihtiyaçlarının gelecek nesillerin kendi ihtiyaçlarını karşılamalarını engellemeyecek, tehdit etmeyecek şekilde giderilmesidir. $\mathrm{Bu}$ çerçevede sürdürülebilir kentsel karayolu ulaşımı ise, gelecek kuşakların yaşamlarına zarar vermeden karayolu trafik güvenliği için gereksinimlerin karşılanmasıdır. Sürdürülebilir Karayolu Ulaşım Politikası, ekonomik kalkınma, teknolojik ve toplumsal gelişmenin etkilerinden faydalanılarak karayolu trafik sorunlarının toplumsal yaşam üzerindeki olumsuz etkilerinin en aza indirilmesi yaklaşımıdır. Tarihsel süreç içerisinde sürdürülebilirlik ile ilgili yaklaşımlar genel itibari ile çevresel sorunlar üzerine şekillenmiştir. Bu çerçevede Transport Canada sürdürülebilir ulaşımı; politikaların hava kirliliğini engelleyecek emisyon çalışmalarına yönlendirilmesi kapsamında ifade etmiştir (www.tc.gc.ca).

Sürdürülebilir kentsel karayolu ulaşım politikalarının temel hedefi; motorlu ulaşım araçlarının kamu kaynakları üzerindeki zararlarını minimize ederek, trafik sıkışıklığını azaltmak ve yönetilebilir bir karayolu sistemi kurmaktır. Sürdürülebilir kentsel karayolu ulaşım uygulamaları noktasında aşağıda belirtilen hususlar ön plana çıkmaktadır (Sutcliffe ve Şenbil, 2016, s. 413-415): 
- Mevcut karayolları sisteminin modernize edilmesi ve bütünleşik bir sistem oluşturulması,

- Kentlerde yayalara ayrılan alanların artırılarak, yaya yollarının geliştirilmesi ve iyileştirilmesi

- Bisiklet kullanımına yönelik yol ve alanların artırılması

- Kent merkezlerinde otomobil kullanımina sinırlamalar getirilmesi, trafik sakinleştirme uygulamalarının artırılması

- Planlı, teknolojik ve sistemli denetim sistemlerinin geliştirilmesi

Trafik sıkışıklığı tüm dünya kentlerinde, bireylerin hayat kalitesini tehdit eden başlica sorunlardan olmaya devam etmektedir. Motorlu taşıt trafiği, kent yaşamına olumsuz etkileri ve neden olduğu ekonomik maliyetler nedeniyle eleştirilmektedir. Bu nedenle çağdaş ulaşım planlamaları genel olarak ulaşım sistemlerini çeşitlendirerek, karayolu ulaşımına talebi azaltmak üzerine inşa edilmektedir (Sutcliffe, 2016b, s. 452). Geleneksel ve çă̆daş ulaşım yaklaşımları arasındaki farklar aşağıda tabloda özetlenmiştir:

Tablo 4. Geleneksel ve Çağdaş Ulaşım Yaklaşımların Özellikleri

\begin{tabular}{ll}
\hline Geleneksel Yaklaşımlar & Çağdaş Yaklaşımlar \\
\hline Ulaşım talebinin planlanması & Ulaşım talebinin yönlendirilmesi \\
\hline Taşıta öncelik verilmesi & Insanlara öncelik verilmesi \\
\hline Ek kapasite oluşturma & Mevcut altyapıyı verimli kullanma \\
\hline Araç kullanıcılarının sorunlarına yönelme & Toplumun sorunlarını dengeleme \\
\hline Büyük sermayeli yatırımlar & Gerçekleştirilebilir küçük yatırımlar \\
\hline Katı kararlar & Esnek kararlar \\
\hline Fiziksel çözümler & Yasal, yönetimsel, ekonomik çözümler \\
\hline Araçlara duyarlılık & Çevreye duyarlılık \\
\hline
\end{tabular}

Kaynak: Elker, 2016, s. 453

\section{Karayolu Trafik Güvenliğinde Anahtar Risk Faktörleri}

Dünya Sağlık Örgütü (WHO), karayolu trafik güvenliği konusunda dünya ülkelerine, trafik kazalarında maddi, manevi zararları azaltmak için beş risk faktörü üzerinde durulması gerektiğini vurgulamaktadır. Araç, yol kullanıcıları ve çevreyi içeren bütüncül politikalarla yani, trafik cezası, trafik işaret ve kurallarını kapsayan yasal düzenlemeler, trafik güvenliğinde farkındalık oluşturacak kampanyalarla hedeflenen sonuçlara ulaşılabileceğini belirtmektedir (WHO, 2015, s. 9-13). Dünya Sağllk Örgütü'nün ifade ettiği risk faktörleri şunlardır:

\section{- Hiz}


- Alkollü araç kullanma

- Emniyet kemeri

- Kask ve teçhizat

- Çocuk koltuğu

WHO 2017 yılında yayımladığı "Save Lives: A Road Safety Technical Package" isimli raporda yukarıda belirtilen risk faktörlerini içeren daha geniş bir öneri listesinin uygulanmasını önermiştir. WHO'nun tavsiye listesinde ifade ettiğ $\mathrm{i}$ trafik güvenliği yönetim faaliyetleri şunlardır (WHO, 2017, s. 14):

- Hız Yönetimi: Şehir ve şehirlerarası hız limitleri yasal olarak belirlenerek uygulanmalıdır. Trafiği sakinleştirme hedefi kapsamında yollar yeniden düzenlenmelidir. Araçlar, teknolojik gelişmelerden yararlanılarak hız konusunda sürücülere yardımcı olacak şekilde üretilmelidir. - Yol Güvenliğinde Lider Kurum: Yol güvenliği konusunda lider bir kurum belirlenmelidir. Yol güvenliği noktasında stratejiler belirlenmeli ve kaynak oluşturulmalıdır. Yol güvenliği stratejilerinin etkileri değerlendirilmelidir. Yol denetleme sistemleri genişletilmelidir. Kampanyalar, eğitimler ve kamu spotları ile farkındalık arttırılmalıdır.

- Karayolları Altyapı Sistemi: Engeller, bariyerler ve diğer düzenlemeler ile yollar, kavşaklar daha güvenli hale getirilmelidir. Yolların birleştiği noktalarda katılan yollar için ayrı cep oluşturulmalıdır. Araç girişinin yasak olduğu bölgeler arttırılarak yayalara öncelik tanınmalıdır. Konut, iş yeri ve okul bölgelerinde trafik sınırlandırılmalıdır. Toplu taşıma faaliyetleri teşvik edilmelidir.

- Güvenli Araç Standartları: Motorlu araçlar ile güvenli seyahat için emniyet kemeri, kask, çocuk koltuğu düzenlemeleri yapılmalıdır.

- Trafik Kuralları: Trafik kazalarını önlemek için geliştirilen trafik işaret, levha ve kurallarına uyulmalı ve bunun denetimi yapılmalıdır.

- Trafik Kaza Sonrası Yönetim: Hastaneler ile entegre acil müdahale sistemleri geliştirilmelidir. Trafik kazalarına müdahale etmek için bireylere ilk yardım eğitimleri verilmelidir.

\section{Türkiye’de Karayolu Trafik Güvenliği Yönetiminde Güncel Uygulamalar}

Dünya genelinde tartışılan trafik güvenliği konusu, Birleşmiş Milletler'in (BM) de çalışmalarına dâhil edilmiş ve 2010 yılında yapılan toplantıda "Küresel Yol Güvenliğinin İyileştirilmesi" hakkında 64/255 sayılı karar alınmıştır. Bu karar çerçevesinde 2011-2020 yılları arasında trafik güvenliğinin sağlanması ve trafik kazalarından kaynaklı ölüm oranlarının azaltılması için "Yol 
Güvenliği için On Yıllık Eylem Planı 2011-2020" kararı ile üye devletler, on yıllık eylem planlarını açıklamaya davet edilmiştir (Karayolu Trafik Güvenliği Stratejisi ve Eylem Planı, 2012). Trafik Güvenliği Eylem Planlarının genel hedefi temel olarak, trafik kazalarında ölen ve yaralananların sayısının, planın uygulanmaya başladığı tarihten itibaren 10 yıllık bir süre içerisinde azaltmaktır. İsveç'teki "Vizyon Sıfır" ve Hollanda'daki "Sürdürülebilir Güvenlik" programların trafik güvenliği noktasında örnek uygulamalar olarak göstermek mümkündür (Payam, 2012: 23). Türkiye de BM'nin daveti kapsamında, karayolu trafik güvenliği stratejisi ve eylem planı çerçevesinde özetle (Karayolu Trafik Güvenliği Stratejisi ve Eylem Planı, 2012):

- Trafik güvenliği konusunda farkındalık oluşturmak için proje, kampanya, konferans, seminer, sergilerin düzenleneceği, afiş, broşür ve kitapçıkların hazırlanarak halka ulaştırılacağı,

- Ulusal ve yerel basın-yayın kuruluşlarınca trafik güvenliğine katkı sağlayacak içerikli yayınların yapılacağı,

- Trafik güvenliği ile ilgili kurum ve kuruluşların kendi görev alanları ile ilgili olarak gerekli çalışmaları gerçekleştireceği,

- Trafik güvenliğine ilişkin risk ve tehlikeleri en aza indirebilmek amacıyla özellikle altyapı çalışmalarının yapılacağı,

- Trafik yönetiminde; teknolojiden yararlanılarak modern tekniklerin kullanılacağı,

- Hız, alkol, emniyet kemeri, kırmızı 1şık ihlalleri, kask ve cep telefonu kullanımı denetimleri başta olmak üzere tüm denetimlerin etkinliğinin arttırılacağı,

- Bütün öğrencilerin trafikte; yaya, yolcu ve bisiklet sürücüsü olarak bilinçli yol kullanıcısı olmalarını sağlayıcı eğitim programlarının hayata geçirileceği ifadelerinde bulunulmuştur.

İçişleri Bakanlığı, 2018 yılı Türkiye'nin ilk 100 günlük eylem planında trafik güvenliği ile ilgili olarak ifade edilen "bir önceki yılın aynı dönemine göre denetimlerin $\% 2$ oranında artırılarak, ölümlü ve yaralamalı trafik kazalarmın $\% 2$ oranında azaltılması" hedefi çerçevesinde bilgilendirme, denetim ve algı yönetimi konularında çalışmalarına hız kazandırmıştır. Bu kapsamda sürücülere yönelik algılanan yakalanma riski duygusunu yüksek seviyelerde tutmak için, uygunsuz şerit kullanımı, yanlış şerit değiştirme, araçla uygunsuz yerde bekleme, hatalı sollama, yanlış duraklama ve park etme gibi ihlallerin önlenmesi için "havadan trafik denetimi uygulaması" başlatılmıştır. 
Havadan trafik denetimi çerçevesinde özellikle trafiğin yoğun olduğu kavşak ve yollarda, kent trafiğinin en üst seviyelerde seyrettiği sabah, akşam mesai başlama, bitiş saatlerinde ve cuma, pazar, pazartesi günleri ağırlıklı olmak üzere helikopter ve drone kullanılarak trafik denetimleri gerçekleştirilmektedir. Denetimler, trafik kazalarına neden olabilecek unsurlar üzerinde, yer trafik ekipleri ile koordineli olarak yürütülmektedir. Emniyet Genel Müdürlüğü (EGM) Havacılık Daire Başkanlığı ve il trafik denetleme şube müdürlükleri denetimler dâhilinde bilgi paylaşımına önem vermektedir.

İçişleri Bakanlığı, “Bu yolda hep birlikteyiz” projesi ile 2018 yılı Eylül, Ekim ve Kasım ayların kapsayan 100 günlük eylem planı çerçevesinde, emniyet kemeri kullanımının yaygınlaştırılması, araçla seyir halinde cep telefonu kullanımının önlenmesi, aşırı hız yapılmasının önüne geçilmesi kapsaminda, Türkiye genelinde 22 bin 490 trafik personeline ek olarak 230 bin emniyet personelinin belirtilen proje dâhilinde denetim faaliyetlerinde görev almasını sağlamıştı (İçişleri Bakanlığı, 2018). İl düzeyinde denetimlerin yapılacağı noktalar konusunda, istatistiki verilerden yararlanılarak, belirlenen kaza kara noktalarına ${ }^{1}$ yönelik özel önlem ve denetim planlamaları başlatılmıştır.

Trafikte bireyler üzerinde olumlu davranış değişikliği gerçekleştirmek ve trafik sorununa çözüm üretmek için, iletişim faaliyetleriyle kamu, sivil toplum ve medya kuruluşlarından oluşan platformlar oluşturulmuştur. $\mathrm{Bu}$ platformlar sayesinde toplumda trafik güvenliği konusunda çok sayıda faaliyet gerçekleştirilmiştir. Bu faaliyetler, trafik güvenliği noktasında düşük maliyetli ancak etkili ve farkındalık yaratan önemli uygulamalar olmuştur. İlköğretim okullarında "Can Dostları Hareketi", "Trafikte Gençlik Hareketi” ve servis şoförlerine yönelik olarak "İyi Dersler Şoför Amca" projeleri uygulamaya konulmuş olup, projeler, uygulanmaya devam etmektedir (MEB, 2018, s. 26). 2018 yılı içerisinde, 4-17 yaş aralığındaki "774 bin 212" çocuğa yönelik trafik eğitimi verilmiş, strateji ve mevzuat düzenlemeleri ${ }^{2}$ yapılmıştır (İçişleri Bakanlığ1, 2018). "Tuzak radar uygulamasının kaldırılması", "trafik polislerinin görünürlüğünün artırılması", "trafik uygulama politika belgesinin

\footnotetext{
${ }^{1}$ Karayolları Genel müdürlüğü (KGM), 2018 yılı sonuna kadar 80 adet kaza kara noktasının iyileştirilmesi için 60 milyon lira harcama yapacağını ifade etmiştir (www.trthaber.com). ${ }^{2} 2018$ yılı Ekim ayında Karayolları Trafik Kanunu'nda yapılan değişiklikle, trafik güvenliğini tehlikeye atan davranışlara yönelik trafik cezaları arttırılmıştır.
} 
oluşturulması ${ }^{3 "}$ gibi tedbirlere başvurulmuştur. Maket trafik aracı uygulaması kapsamında 582 maket trafik polisi aracı yerleştirilmiş ve yerleştirilen bölgelerde trafik kazalarında \%17,5 oranında azalma kaydedilmiştir. Kamu spotları ve afişs-broşür çalışmaları neticesinde farkındalık oluşturulmuştur (İçişleri Bakanlığı, 2018).

Türkiye'de son ylllarda önem kazanan trafik güvenliği konusunda sempozyum ve sergilerin çatısı altında, panellerin yanı sıra tiyatro, boyama etkinlikleri gibi çocuklara yönelik sosyal etkinlikler düzenlenmektedir. Kamu kurumları, özel sektör kuruluşları, STK yetkilileri ve trafik güvenliği konusunda duyarlı tüm vatandaşların bir araya geldiği bu organizasyonlarda, çok sayıda panelistin katılımı ile nitelikli bilgi paylaşımı gerçekleşmektedir.

Psiko-Teknik Değerlendirme ve Test İşlemlerine İlişkin Uygulama ve Esaslarla ilgili Yönetmelik kapsamında, UKOME kararı ile il sınırları içerisinde, toplu taşıma hizmeti veren araçlarda, halen çalışmakta olan şoförleri, yeni işe başlayacak şoförleri ve İdare Encümeni'nin uygun göreceği şahıs ve kurum şoförlerini kapsayan, bilgisayar destekli psiko-teknik test uygulaması getirilmiştir (UKOME, 2017, s. 2).

Karayolları Genel Müdürlüğü yol geometrisinde iyileştirme, kavşak düzenlemesi, bölünmüş yol yapımı, şerit genişletilmesi, banket düzenlemesi gibi çalışmalarını hızla devam ettirmektedir. Özellikle konut araları ve okulların bulunduğu bölgelerde, yaya yoğunluğunun fazla olduğu kritik noktalarda uygulanan trafik sakinleştirme ${ }^{4}$ işlemlerine, yani; sürücüleri dikkatli araç kullanmaya yönlendirerek trafik güvenliğini artırmayı hedefleyen fiziksel düzenlemelere hız kazandırılmıştır (Sutcliffe, 2016, s. 441-442).

Türkiye'de Fahri Trafik Müfettişi görevlendirilme sayısının yönetmelik hükümlerine göre, tescilli araç sayısının binde ikisi kadar olması gerekmektedir. Bu hedefe her yıl ulaşılması planlanmaktadır. Ayrıca Fahri Trafik Müfettişlerine yılda en az iki defa eğitim verilerek denetim kapasitesinin arttırılması, denetim etkinliğinin sağlanması, kural ihlallerinde algılanan yakalanma riskinin maksimum düzeye ulaştırılması hedefi ile hareket edilmektedir (Karayolu Trafik Güvenliği Stratejisi ve Eylem Planı, 2012).

\footnotetext{
${ }^{3}$ Trafik Güvenliği Uygulama Politika Belgesi, denetim, kaza sonrası acil müdahale, personel eğitimi, projeler ve düzenleme yapılacak konular olmak üzere beş temel başlıktan oluşmaktadır.

${ }^{4}$ Trafik Sakinleştirme Araçları: Hız kesici yol kasisleri, tümsekler, yol kaplamaları, döner kavşaklar ve adalardır.
} 


\section{Sonuç}

Kent içi sosyal hayatın en önemli bileşenlerinden bir tanesi olarak karayolu trafik güvenliği, bireylere sunduğu imkânlar kadar sebep olduğu kaza riskleri itibari ile de sosyal hayatı tehdit eden önemli bir sorundur. Türkiye' de ulaşım faaliyetlerinin \%90'lık bölümü karayolu ile gerçekleştirilmektedir. Toplu ulaşım sistemlerinin içerisinde karayollarının bu seviyede tercih edilmesi, konu üzerinde iyileştirme çalışmalarının yapılmasını gerektirmektedir. Türkiye'de trafik kazalarındaki ölüm sayısı Avrupa ülkeleri ile kıyaslandığında, trafik kazalarının Türkiye için oluşturduğu tehdidin boyutu kendini göstermektedir. Özellikle 2015 yılı itibari ile kaza sonrası gerçekleşen ölüm oranlarının da istatistiklere dâhil edilmesi, trafik kazalarına yönelik yeni sürdürülebilir kentsel karayolu ulaşım politikalarının gerçekleştirilmesi ihtiyacını ortaya çıkarmaktadır. Sürdürülebilir kentsel karayolu ulaşım politikalarının temel hedefi; motorlu ulaşım araçlarının ve trafik kazalarının kamu kaynakları üzerindeki zararlarını azaltarak, trafik sıkışıklığını azaltmak ve yönetilebilir bir karayolu sistemi kurmaktır.

Kent içi karayolu trafik güvenliği için ilk adım olarak araçlardan önce bireylere yönelik politikalara öncelik verilmelidir. Karayolları dışındaki diğer toplu taşıma sistemleri geliştirilerek, karayolu trafik yoğunluğunun geliştirilen bu sistemlere kaydırılması önemlidir. Günümüzde bir toplumsal statü göstergesi olan özel otomobil kullanımının azaltılması noktasında çalışmalar yapılmalıdır. Mevcut Karayolu ağlarının güvenli ulaşım çerçevesinde yeniden düzenlenmesi yapılmalı, yeni yollar, kaza kara noktaları oluşmaması için iyi bir mühendislik çalışması sonrasında gerçekleştirilmelidir. Karayolları altyapı sistemleri belediye hizmetleri dâhilinde gözden geçirilmelidir. Trafik sakinleştirme çalışmaları özellikle konut, okul ve iş yeri çevrelerinde yoğunlaştırılmalıdır. Trafik güvenliği noktasında farkındalık oluşturmak için yerel ve ulusal yayınlar önem arz etmektedir. Kamu spotları, projeler basın ve yayın kuruluşlarınca desteklenmelidir. Trafik kazalarında insan faktörünün oynadığı rolün büyüklüğü düşünüldüğünde, küçük yaşlardan başlayan sistematik bir trafik eğitiminin hayata geçirilmesi gerekmektedir. Trafik eğitiminin özellikle küçük yaşlarda uygulamalı olarak gerçekleştirilmesi, hedeflenen trafik güvenliği farkındalığının yetişkin insanlarda oluşması için önemli bir uygulama olarak görülmektedir. Yol kullanıcıları üzerinde yakalanma risk algısını arttırmak için trafik denetim personeline de önemli görevler düşmektedir. Denetim personeli periyodik 
eğitimlerden geçirilmeli ve denetim personelinin trafikte görünürlügünün arttırılması sağlanmalıdır.

Türkiye sürdürülebilir karayolu trafik güvenliği çerçevesinde özellikle BM'nin küresel yol güvenliği tavsiye kararları sonrasında bir eylem planı oluşturmuş ve trafik kazalarının sebep olduğu maddi, manevi kayıpları en aza indirmek için çok boyutlu politikalar geliştirmiştir. Bu politikalar çerçevesinde yol güvenliği ile ilgili kurum ve kuruluşlar özelinde çalışmalar hız kazanmıştır. Trafik güvenliği algısını sürekli güncel tutma konusunda çocuk ve yetişkinler özelinde kampanya, sempozyum ve sergiler düzenlenmektedir. Trafikte algılanan yakalanma riskini arttırmak için İçişleri Bakanlığı'nın tüm emniyet teşkilatı personelini trafikte görünür hale getirmesi önemlidir. Ayrıca İçişleri Bakanlığı'nın drone ve helikopter gibi hava araçlarını da trafik denetimlerine dâhil etmesi konuyu çok boyutlu ve ciddi olarak değerlendirdiğini göstermektedir. Yine teknolojik gelişmelerden faydalanılarak elektronik denetleme sistemlerinin yaygınlaştırılması karayollarında daha dikkatli ve kurallara uygun hareket edilmesini beraberinde getirmiştir. Çocuk trafik eğitimlerinde trafik parklarının yaygınlaştırılması ve uygulamalı eğitimler düzenlenmesi küçük yaşlarda trafik güvenliği bilincinin oluşması için başarılı bir uygulama olmuştur.

Bu çalışmada, kent içi karayolu trafik güvenliğine ilişkin temel risk faktörleri incelenmiş ve trafik kazalarında, artan taşıt sayısına oranla bir azalma olduğu vurgulanmıştır. Bu çerçevede trafik güvenliğinin sağlanmasına yönelik yapılan yatırımların ve geliştirilen politikaların etkili olduğu değerlendirilmektedir. Bu çalışmanın, trafik güvenliğine ilişkin geliştirilen politikaların trafik kazalarına etki eden risk faktörlerinin azaltılmasındaki etkinliğinin değerlendirilmesine katkı sağlayacağı düşünülmektedir. 


\title{
Extended Abstract
}

\section{City-Road Traffic Safety in the Framework of Current Policies}

\author{
Ozan Kavsırac1 \\ Turkish National Police Academy
}

Nowadays, the spread of cities to large areas brings along the necessity to use transportation vehicles. While cities are expanding rapidly, accessibility and capacities of transportation vehicles cannot reach this speed. This raises an increasing traffic problem for urban residents. Traffic-related problems lead to material and moral losses for states and individuals. Preventing possible losses and ensuring road traffic safety has become an important social problem for state administrations. Road traffic safety; it is a multifaceted issue involving possible problems between the environment, vehicle and human components and the methods developed against these problems. The realization of highways by about $90 \%$ of freight and passenger transport in Turkey, at high levels leads to the risk of traffic accidents and road traffic safety makes the more important.

Cities are places where economic activities are carried out intensively and most of the population resides. For this reason, urban and pedestrian traffic is very high. The higher the density of people, the higher the risk of traffic accidents. Because when we look at the traffic accidents occurred in Turkey and the world seems to be one of the biggest flaws of human interests. It is understood that the role played by people in traffic accidents is important only when we evaluate the traffic participants not only as pedestrians but also as passengers.

Highways are the basis of urban transport in Turkey. In order to minimize the negative effects of road traffic problems on social life, the importance of developing sustainable urban road transport policies is increasing. The objective of sustainable road transport policies is to minimize traffic congestion 
and to establish a manageable road system by minimizing the damage of motor vehicles on public resources. Motor vehicle traffic is frequently criticized for its negative effects on urban life and economic costs it causes. For this reason, modern transportation planning is generally based on diversifying transportation systems and reducing the demand for road transport.

The World Health Organization (WHO) recommends that the world countries on road traffic safety should focus on five risk factors for reducing material and moral damages in traffic accidents. These factors are the use of speed, alcoholic driving, safety belt, helmet and equipment, child seat. Within the framework of these risk factors, the WHO listed the traffic safety management activities as follows: Speed management, identifying a leading road safety organization, improving the road infrastructure system, setting safe vehicle standards, exhibiting and observing behavior in accordance with traffic rules, and monitoring the management emergency response system after traffic accidents.

The issue of traffic safety, discussed throughout the world, has been included in the work of the United Nations and, with the decision of "Ten Years Action Plan for Road Safety 2011-2020", member states have been invited to explain their ten-year action plans to ensure traffic safety. Turkey as part of an invitation to the $\mathrm{UN}$, within the framework of road traffic safety strategy and action plan, Creating an awareness of traffic safety, making infrastructure works, benefiting from technology, traffic management, increasing the effectiveness of the inspections, the training program will support to be conscious road users subject realization studies have said that done.

Studies in ensuring road safety in Turkey has gained momentum. 2018 Turkey's first 100-day action plan expressed regarding traffic safety "increased by $2 \%$ of controls compared to the same period of the previous year, and this mortal wounds should be a $2 \%$ reduction of traffic accidents" informing the objective, practices in auditing and perception management issues has been implemented.

In the context of airborne traffic control, traffic inspections are carried out by using helicopters and drones, especially at the intersections and roads where traffic is dense, city traffic is at peak levels, morning, evening, beginning, end times and on Friday, Sunday and Monday. The inspections are carried out in coordination with the ground traffic teams on the elements that may cause traffic accidents. EGM Aviation Department and provincial traffic supervisory branch directorates attach importance to information sharing within the scope of audits. Ministry of Interior, within the 
framework of the 100-day action plan, dissemination of safety belt use, prevention of cell phone usage cruising vehicle, covered to prevent the making excessive speed, Turkey has made of his taking part in audit activities across the 230.000 security personnel.

In order to achieve positive behavior change on the individuals in traffic and to find solutions to the traffic problem, platforms of communication, public and non-governmental organizations and media organizations have been established. Thanks to these platforms, many activities have been carried out in the area of traffic safety. In the primary schools, "Can Dostlar Hareketi" "Trafikte Gençlik Hareketi" and "İyi Dersler Şoför Amca" projects were put into practice. Symposium, exhibitions, panels, theater and painting activities and social activities are organized for children. Symposium, exhibitions, panels, theater and painting activities and social activities are organized for children.

Within the scope of the model traffic vehicle application, 582 models of traffic police vehicles were installed and a $17.5 \%$ reduction in traffic accidents was recorded in the settlements. General Directorate of Highways continues its activities such as road geometry improvement, intersection arrangement, split road construction, strip expansion and banquet arrangement. Especially in areas where there are housing breaks and schools, traffic calming procedures applied at critical points where speed density is high are accelerated.

Turkey in the framework of sustainable road traffic safety in particular have created an action plan after the decisions recommended UN global road safety and property caused by traffic accidents, spiritual losses has developed a multi-dimensional policies to minimize. Within the framework of these policies, studies on road safety related institutions and organizations have accelerated. Campaigns, symposiums and exhibitions are organized for children and adults to keep the perception of traffic safety up-to-date. It is important that the Ministry of Interior make all the police personnel visible in traffic to increase the risk of being detected in traffic. In addition, the Ministry of the Interior's drone and helicopter, such as air vehicles in the traffic controls to include the issue shows that the multi-dimensional and serious. Again, the use of technological developments to spread electronic audit systems has brought along more careful and rules of action on highways. Extending traffic parks and organizing practical trainings in children's traffic trainings has been a successful application for raising awareness of traffic safety at an early age. 
In this study, the main risk factors related to urban road traffic safety were examined and it was emphasized that there was a decrease in traffic accidents compared to the number of vehicles. In this context, it is considered that the investments and policies developed to ensure traffic safety are effective. It is thought that this study will contribute to the evaluation of the effectiveness of the policies on traffic safety in reducing the risk factors affecting traffic accidents.

\section{Kaynakça/References}

Akbulut, F. (2016). Kentsel ulaşım sistemlerinin planlanmasi ve yönetiminde sürdürülebilir politika önerileri. Kastamonu Üniversitesi İktisadi ve İdari Bilimler Fakültesi Dergisi, 11, 336-355.

Ankara Ulaşım Koordinasyon Merkezi (UKOME). (2017). Psiko-teknik değerlendirme raporu (Karar No. 2017/13). Ankara, Büyükşehir Belediyesi.

Elker, C. (2016). Ulaşım Politikalarında Çağdaş Yaklaşımlar. M. Ersoy (Der.), Kentsel planlama ansiklopedik sözlük içinde (453-455). Ankara: Ninova Yayınları.

Özdemir, S. (2010). Türkiye'de örgün sistem içerisinde trafik eğitiminin durumu; Avrupa ve dünya ülkeleri işiğinda geliştirilmesi. (Yayımlanmamış yüksek lisans tezi). Polis Akademisi Başkanlığı, Güvenlik Bilimleri Enstitüsü, Ankara.

Payam, M. M. (2012). Ilk ve ortaöğretim okullarinda trafik eğitimindeki temel sorunlar: Siirt ili örneğgi. (Yayımlanmamış doktora tezi). Polis Akademisi Başkanlığı, Güvenlik Bilimleri Enstitüsü, Ankara.

Sutcliffe, B. E. (2016a). Trafik sakinleştirme. M. Ersoy (Der.), Kentsel planlama ansiklopedik sözlük içinde (441-442). Ankara: Ninova Yayınları.

Sutcliffe, B. E. (2016b). Ulaşım ana planı. M. Ersoy (Der.), Kentsel planlama ansiklopedik sözlük içinde (452). Ankara: Ninova Yayınları.

Sutcliffe, B. E. Şenbil, M. (2016). Sürdürülebilir ulaşım ve politikası, M. Ersoy (Der.), Kentsel planlama ansiklopedik sözlük içinde (413-416). Ankara: Ninova Yayınları.

Şenbil, M. (2016). Kentsel Ulaşım. M. Ersoy (Der.), Kentsel planlama ansiklopedik sözlük içinde (60-62). Ankara: Ninova Yayınları.

T.C. Başbakanlık. (2012). Karayolu trafik güvenliği stratejisi ve eylem plani hakkinda genelge (Resmi Gazete, Sayı. 28370). Ankara, 02 Ekim 2018 tarihinde http://www.trafik.gov.tr/SiteAssets/Yayinlar/Kitaplar/Karayolu Trf Guv eylem plan\%C4\%B1.pdf adresinden erişildi.

T.C. Milli Eğitim Bakanlığı. (2018). Trafik genel eğitim planı. Ankara, Özel Eğitim Kurumları Genel Müdürlüğ̈̈.

T.C. İçişleri Bakanlığı. (2018). İçişleri bakanı Süleyman Soylu'nun konuşmaları. Ankara, Basın Halkla İlişkiler Müşavirliği, bu yolda hep birlikteyiz projesi tanıtım 
toplantısı. 03 Ekim 2018 tarihinde,https://www.icisleri.gov.tr/bu-yolda-hepbirlikteyiz-projesi-tanitim-toplantisi adresinden erişildi.

Transport Canada. (2018). Sustainable development in transport Canada. 2017-2020 departmental sustainable development strategy. 11 Ekim 2018 tarihinde https://www.tc.gc.ca/en/transport-canada.html adresinden erişildi.

TRT Haber, (2018). Karayolları trafik güvenliği için çalışma başlattı başlıklı haber. 03 Ekim 2018 tarihinde https://www.trthaber.com/haber/turkiye/karayollari-trafikguvenligi-icin-calisma-baslatti-359190.html adresinden erişildi.

Türkiye İstatistik Kurumu (TÜİK). (2018). Ulaştırma istatistikleri. Ankara: TÜİK

Yurdakul, A., Turan, D., Çomaklı, E. Ş. (2017). Kamusal düzenleme olarak sürücü belgesi verilmesinin (trafik eğitiminin) özel kuruluşlara devrinin sosyo-ekonomik maliyetleri. Uluslararası Trafik ve Ulaşım Güvenliği Dergisi, 3(1), 17-30.

World Health Organization (WHO). (2015). Road safety media brief. Switzerland. 05 Ekim 2018 tarihindehttp://www.who.int/violence injury prevention/publications/road traffic/Road safety media brief full document.pdf_adresinden erişildi.

World Health Organization (WHO). (2017), Save lives: A road safety technical package. Switzerland. 01 Ekim 2018 tarihinde http://apps.who.int/iris/bitstream/handle/10665/255199/9789241511704-eng.pdf?sequence=1\&isAllowed=y adresinden erişildi.

Ozan Kavsıracı, 1987 yılında Denizli'de doğdu. İlköğretimini bu şehirde, orta öğretimini ise Ankara'da tamamladı. 2010 yılında Polis Akademisi Başkanlığı'ndan mezun oldu. Yüksek lisans öğrenimini Polis Akademisi Başkanlığı Güvenlik Bilimleri Enstitüsü Ulaşım Güvenliği ve Yönetimi bölümünde, doktora öğrenimini Polis Akademisi Başkanlığı Güvenlik Bilimleri Enstitüsü Güvenlik Stratejileri ve Yönetimi bölümünde tamamladı. 2010-2014 yılları arasında İzmir İl Emniyet Müdürlüğü'nde, 2014-2015 yılları arasında Polis Akademisi Başkanlığı'nda çalıştı 2015 yılının Kasım ayından itibaren ise Polis Akademisi Güvenlik Bilimleri Enstitüsü'nde araştırma görevlisi olarak görev yapmaktadır.

Ozan Kavsıracı, He was born in Denizli in 1987. He studied primary school in this city and he studied high school in Ankara. In 2010, he graduated at Turkish National Police Academy. He completed his master degree at Police Academy of Transport Security and Management Department. He completed his Phd degree at Police Academy of Security Strategies and Management Department. He had worked in İzmir police department between 2010-2014 and had worked in Police Academy between 2014-2015. He has been still working at Turkish National Police Academy as a research asistant since 2015.

E-mail: ozankavsiraci@gmail.com

\section{Kaynakça Bilgisi / Citation Information}

Kavsıracı, O. (2018). Güncel Politikalar Çerçevesinde Kent İçi Karayolu Trafik Güvenliği. IDEALKENT - Kent Araştırmaları Dergisi, 25, 960-979. 